\title{
Fight against Absenteeism in the Public Service in France and the United Kingdom: Towards a Comprehensive approach of the Problem
}

\author{
Claude BARREIX \\ Visiting Professor, Paris-Est Créteil University, AEI Institute \\ 61 avenue du général Degaulle 94010 Créteil \\ E-mail : claude.barreix@u-pec.fr
}

Accepted: July 17, 2012 Published: August 15, 2012

Doi:10.5296/ijhrs.v2i3.2245 URL: http://dx.doi.org/10.5296/ijhrs.v2i3.2245

\begin{abstract}
The purpose of this study was to put forward the concerns related to absenteeism due to sickness in the public services and the ways to fight against it.

Based on two examples drawn from UK Royal Mail company and French local authority experiences, this study considers first of all two main means of tackling absenteeism, currently used in numerous entities both public and private: coercive measures through medical controls and financial incentives. Even if these bodies got good results in using these two levers, these turned out not to be sufficient enough, on their own, to really tackle absenteeism.

However Royal mail and certain French local authorities have met this better challenge in implementing a comprehensive approach of the phenomenon which did not neglect repressive and reward actions but introduced the measure and monitor of sick leaves. They also introduced in their human resource management appropriate managerial measures, particularly related to communication, and specific actions tending to improve the employees' health and well being at work

The study presents some assessing elements tending to show the efficiency of a holistic approach of absenteeism.
\end{abstract}

Keywords: Absenteeism Control; Incentive; Managerial Actions; Health, Well-Being at Work 


\section{Introduction}

In these times when all governments are looking for budget savings, deficit reducing, the question of the fight against absenteeism of staff who run public services is particularly topical.

Traditional means tending to 'bring back staff to work' regularly come back into the spotlight: medical controls, which have some efficiency, are increasingly strengthened and the threat of financial sanctions is even brandished. The introduction of a waiting period for French civil servants could also discourage short sick leaves medically unjustified and can save some 30 million euros per year, the government says.

These steps have been completed over the years by direct financial incentives in the form of bonuses say 'attendance bonuses', paid to agents who do not take sick days, which only have been used in local authorities and hospitals. Most original initiatives were taken in other countries. We cite the case of the UK's Royal Mail which has organized from 2005 to 2007 a lottery for a prize of some value, for the benefit of post service employees, permanently present in their workplace during a period of 6 months or a year.

However all these methods have limitations and insurers and employers have taken that into account by focusing in more recent years on the issue of well-being at work, a concept that refers to both managerial practice and the health protection of workers. In France, Dexia Sofcap, insurer of personnel of local authorities and Royal Mail in the UK, follow this logic considering that the management of absenteeism at work cannot be limited to taking enforcement action and / or incentives, against the defaulting officers but should be a broader process including both managerial and medical-psychological supports.

\section{Necessary but insufficient controls}

Absenteeism in the public service is a phenomenon found in all countries. In France the figures are advanced tending to show that absenteeism rate ${ }^{i}$ due to sickness is higher in the public sector than in the private sector. The French Institute of Public Administration Research (IFRAP) a think tank which often highlights shortcomings in public service even announces that in the local authorities, recorded absenteeism is almost twice that of the private sector: the absenteeism rates (including maternity and accident at work leaves) are respectively 11.3 and $5.5 \%$ in 2004 . According to this institute the explanation for this result is found in the lack so far in the public sector, of a waiting period and a great generosity of the Civil Service which gives to personnel, significant benefits in terms of compensation of sick leave, especially when it comes to time off for serious or prolonged illness. The annual financial cost to society of sick leaves in the whole French civil service advanced by the IFRAP would be about 7 billion euros per year.

In local authorities, Dexia Sofcap has estimated that absenteeism rate for sickness (excluding maternity and accident at work leaves) is between 5.9 and $8.7 \%$ according to the size of the bodies and the average direct costs are between 1171 and 1798 euros per agent, which must be multiplied by 3 or 5 when taking into account indirect costs as absenteeism management in the directorate in charge with human resource, replacement of sick employees, drop of Quality of Service... 
In order to limit sick leaves, the French government decided in 2010 and through 2012 to experiment a procedure limited to state services of five departments and the central economic and financial ministries, entrusting the National Fund Health Insurance (CNAM) with the control of civil servants concerned. So physician controllers from the CNAM, whose specialty is to control sick workers in the private sector, have been replacing private doctors usually appointed by the Administration to ensure the justifiability or otherwise of some sick leaves. An automated information system was set up too to monitor absences and their control. At the end of this experiment period an assessment will show if this process must be continued and extended to the whole state services.

This absence monitoring is an essential approach. Today ministries, local authorities and other public bodies produce official statistics focused on the causes of non-attendance, identified in a base day or simply make an annual snapshot of overall absenteeism during the past year without producing the results by administrative unit, out of a process that could allow to reveal disparities between services and lead to real thinking on the subject. These figures are mostly published in the annual social report and are not often completed by commentaries. But the apprehension of a phenomenon should necessarily pass through the establishment of an information system fed continuously, which allows to measure and also to objectify and to relativize the phenomenon and eventually to find appropriate means to tackle the problem.

For example Dexia Sofcap company offers its members of local authorities an online reporting system of sick leaves, together with a precise tracking of statistics, with automatic calculation of indicators to help them better manage absenteeism due to sickness. Dexia Sofcap is counting on a group of 1500 medical experts who are commissioned in order to control employees who get numerous and/or longer sick leaves. These controls seem to be efficient and reveal that from $10 \%$ to $13 \%$ of the employees controlled would benefit from unjustified sick leaves and physician controllers prescribe them to return to work.

\section{Financial incentives and their limits}

Some French local authorities have developed financial incentives to fight against absenteeism of their agents. The 'attendance bonus' does not appear as a new bonus the legality of which may be contested, but as a different form of payment of pre-existing compensation. We could quote municipalities such as Montpellier, Agde, Douarnenez... which have got experience in this field. These bonuses are little more than a EUR 50 monthly per agent.

These incentives are more or less felt as unfair by the employees because if they can act as a driving force to deter certain agents in good shape from turning away from work, they penalize those who are really sick and whose health status fully justifies a sick leave. However they are not fiercely contested because a majority of employees receive them and this bonus ends up belonging to their regular wages.

Moreover this type of incentive was recommended at the end of 2009 by Deputy Jean Luc Warsmann, in charge of a mission to optimize public spending, who states in his report that rather than controlling and punishing public employees, it would be preferable to study the 
implementation of a financial incentive approach, involving public officers in their own attendance. He therefore proposed a bonus to limit the use of sick leaves. This conclusion has not yet followed until now.

However this MPs considers that this bonus is not sufficient and he encourages political authorities 'to investigate the causes of absenteeism in the public service, and identify problems that may involve functioning of the service itself'.

Across the Channel, Royal Mail encountered in 2004 a problem with postmen taking an average of twelve-day sick leaves every year, compared with a seven-day average across British industry.

Between 2005 and 2007, this company set up a lottery restricted to those employees who did not take a sick leave over the past six months and which at least involved over half of its 170,000 employees.

34 "Ford Focus" cars and 75 holiday vouchers worth $£ 2000$ were distributed in the first year. After the first 6 months, the daily attendance had increased by $10 \%$ or the equivalent of 1,000 additional employees present each day for the whole group. In 2006 the increase was 18\% and concerned personnel present during a period of 12 months, a $£ 150$ travel voucher was given to even those of them that the draw had not favored.

Despite its relative success in reducing absenteeism, with a large participation of employees involved in the process, such a policy has been considered as a gimmick by Royal Mail staff and the unions like Communication Workers Union (CWU), which includes Royal Mail employees, considering that most people do not choose to become sick and that the attractiveness of valuable goods are not sufficient to be a unique incentive. Many employees would prefer to get better working conditions to prevent them from being turned away from work.

So this operation has not been extended beyond 2007 and the Royal Mail company has chosen to focus its efforts on a more global approach to attendance management that it had initiated since 2004 and developed simultaneously in organizing its lottery. Royal mail considered that the prize draw was no more useful because it had created a movement inside the company where everybody has spoken about the importance of attendance and the dangers of uncontrolled absenteeism.

\section{Towards a comprehensive approach to absenteeism in the public service}

Beyond the setting up of its lottery, that might be considered as anecdotal, at least on this side of the Channel, Royal Mail has not hesitated to spend $£ 46$ million between 2004 and 2007 in actions to improve the health and well-being of its employees, including training managers in absence management and monitoring their staff during and after their sick leave, in order to achieve an appropriation of the problems related to absenteeism, by all the executives.

The company charged with an audit of its policy of absenteeism management, the London School of Economics, which produced a report on the subject entitled 'The Value of rude health'

This audit has analyzed through individual interviews and surveys the strategy defined and implemented by the company, that led to a total return from 7 to $5 \%$ absenteeism at the end, 
equivalent to an extra 3600 employees at work, with total savings in direct costs of 227 million pounds over the period plus productivity gains, improved Quality of Service and lower expenses related to the replacement of absent staff. Concerning Quality of Service on its own the London School of Economics evaluates that reducing absenteeism contributed to improve net income for the company, for at least $£ 672,000$, between 2004 and 2007.

The preliminary findings made by the Royal Mail have highlighted that over three-quarters of sick leave were not motivated by purely medical motive but stress, harassment at work, personal and family problems, difficulty in combining life at work and family life. Moreover the context was like in numerous companies some employees considered sick leaves as an entitlement while managers were seen as inactive in front of these abuses. That might affect the morale of other employees, discouraged and demotivated who might be kept away from work in turn.

Efforts to fight against absenteeism were based both on a different approach to the relations between employees and their hierarchy and the providing to personnel better medical and psychological support. They particularly concerned postal sites where absenteeism appeared highest, and especially resulted by:

\section{Managerial actions:}

Royal Mail increased delegation of authority for the benefit of local line managers to play an active role in improving attendance in their service, for better monitoring of absences and increased communication with staff, particularly to make them aware of their responsibilities towards the company and the consequences of their absences.

A training program for managers to reduce absences has been set up. These formations could then be put into practice by organizing individual interviews on the initiative of managers, with their employees returning from sick leave. One pitfall to avoid was that these interviews were seen as a rebuke by the employees concerned. These interviews turned out to be particularly useful in some cases to identify any adjustments to be applied to the service organization in the interest of both parties.

Communication has been strengthened as well through weekly 'Work Time Listening and Learning' sessions where managers discuss with their teams about their concerns.

\section{Medical support:}

Royal Mail improved and expanded access to occupational health, especially in the fields of physiotherapy and occupational therapy, particularly with an access to medical service companies as Atos Origin.

These actions were completed by communication programs and raising awareness on health promotion and the pursuit of well-being, including putting forward the fight against smoking, nutrition issues, prevention and treatment of back pain, the means to fight against stress ..

It must be noticed that the link between managerial actions and wellbeing has been highlighted in a survey carried out by the CBI (Confederation of British Industry) which shows that $70 \%$ of managers interviewed thought that praising staff for a job would have a radical impact on absenteeism because it raises their morale. 
The results of this comprehensive policy have been spectacular and the experts of London School of Economics pointed out that a local survey revealed that there was a link between the drop of absenteeism in the postal depots and the employee attendance to Work Time Listening and Learning sessions and better consideration of their issues by managers as well.

In France, Dexia Sofcap but also the National Center for Local Authorities (CNFPT), which manages the local authorities' staff, are working in the same direction.

Dexia Sofcap company allows its members to monitor absences of their staff online, and if necessary to trigger medical controls and provide them with advice about sick leave management. They produce statistics on absenteeism for every unit of the authority and calculate key indicators deemed as essential for the managers before taking a decision.

Moreover they have set up important preventive actions in order to fight against absenteeism. So they have implemented awareness programs and training programs for local employees to help them in understanding the causes of absenteeism and to support the return to work of the agents, including systematic organization of meetings with employees on the day they go back to work, in order to hear them on possible link between their frequent absences and difficulties found in their professional or familial life and to try to give them advice to help them to solve their problems.

The landmark program concerns individual counseling and it is named 'REPERE'. Designed to 'help officers to find an equilibrium and prevent repeated interruptions, regardless of the cause of the difficulties (personal or professional)', the program relies on the participation of 240 psychologists who conduct neutral and confidential interviews. Employees who have difficulties leading them to frequent sick leaves are encouraged, but not obliged, to attend these interviews and their follow up must last one year. The aimed goal is a return to sustainable employment.

CNFPT as for it accompanies a number of initiatives taken by local authorities and tries to bring a holistic approach to the problem of absenteeism particularly taking into account prevention of psychosocial risks. After a diagnosis shared by the directorate of human resource, representatives of occupational health, including psychologists, and representatives of the unions, an action plan is defined.

The example that can be given is that of the Urban Community of Artois.Com (that is to say a group of municipalities) in northern France. The approach started from an assessment of absenteeism that revealed that $18 \%$ of this community working forces were continuously lost, representing 46 jobs and 1.9 million euros. The method used included four main steps:

First of a all follow up of absenteeism is necessary through monthly collection of statistics; Then an Analysis of causes took place through a questionnaire sent to all agents about work life, then the setting up of a "barometer of well-being" to measure the sense of belonging and a reflection to measure suffering at work.

Training actions have been further on organized for the executives, then all agents on 
prevention and employee safety, awareness of stress, conflict prevention; they also covered movements and postures, occupational health and safety.

To conclude on this plan, recognition and sanction have been set up, presenting as an attendance bonus of 51 euros per month for a non-absent, each day of absence reducing of 17 euros this allowance, which is not paid from three days of downtime.

The Urban Community of Artois.com has obtained for its staff reduced absenteeism representing 4 jobs, according to a first assessment.

\section{Conclusion}

It thus appears that a comprehensive approach to absenteeism leads to better outcomes than measures of coercion or encouragement on their own. Management of absenteeism if it also refers to these two levers must be anchored on a continuous measurement of absences, a comparison of results between units, an appreciation of their changes over time. It also requires awareness and training of managers and agents and the intervention of medical and psychological structures to prevent and to reduce psychosocial risks and develop activities that promote good health and well-being of workers. The importance of an efficient communication organized by the directorate of human resource but also diffused inside every working unit seems fundamental.

It is obvious that such a policy presents financial costs that can sometimes seem high but it represents an investment that, as it has been shown, is cost effective given the exorbitant cost of absenteeism. In this respect the auditors at the London School of Economics offer an extrapolation of the approach initiated by Royal Mail to UK 13 economic sectors (the health sector to the wholesale and retail, through the public services) that display the worst performance in terms of personal attendance, and they estimate that the savings would amount to 1 billion 450 million pounds per year.

\footnotetext{
${ }^{\mathrm{i}}$ It corresponds to the ratio: $\mathrm{x} 100$
}

Number of days off due to sickness

Number of employees in the unit $\mathrm{x}$ Number of working days 


\section{References}

David Marsen and Simone Moriconi (May 2008) The value of rude health London School of Economics, Centre for economic performance and Department of Management

Sandrine Gorreri and Léa Camet (2006) Un absentéisme deux fois plus élevé dans le public que dans le privé IFRAP: Institut français de Recherche sur les Administrations Publiques [Online] Available : http://www.ifrap.org/Un-asbenteisme-

deux-fois-plus-eleve-dans-le-public.191.html

Dexia Sofcap : Les étapes essentielles pour réduire l'absentéisme [Online] Available :

http://www.sofcap.com/pilotez-vos-arrets.html

Dexia Sofcap : Soutien psychologique [Online] Available :

http://www.sofcap.com/file/soflink/pj/fiche_soutien_spy_p_h43433.pdf

CNFPT: Centre National de la Fonction Publique Territoriale (2012) Absentéisme et risques psycho-sociaux pour la région Pas de Calais [Online] Available :

http://www.wikiterritorial.cnfpt.fr/xwiki/wiki/econnaissances/view/Echanges-de-Pratiques/A bsenteismerisquespsychosociaux 